\title{
The Impact of Health Service Quality on Patients' Satisfaction over Private and Public Hospitals in Jordan: A Comparative Study
}

\author{
Ahmad Mahmoud Zamil (Associate Prof.) \\ Riyadh Community College, Faculty of Administrative Science \\ King Saud University, P.O.Box 28095, Kingdom of Saudi Arabia \\ E-mail: drahmad764@yahoo.com
}

Ahmad Yousef Areiqat (Assistance Prof.)

Business Administration Dept., Faculty of Administrative \& Financial Sciences

Al Ahliyya Amman University, Jordan

Waleed Tailakh

Researcher, Jordan

$\begin{aligned} & \text { Received: November 19, } 2011 \\ & \text { Accepted: December 19, } 2011 \quad \text { Published: February 1, } 2012 \\ & \text { doi:10.5539/ijms.v4n1p123 }\end{aligned}$ URL: http://dx.doi.org/10.5539/ijms.v4n1p123

\begin{abstract}
This study aimed to measure the Impact of Health Service Quality on Patient's Satisfaction in the Hospital's of Public and Private sectors in Jordan. To attain the aim of this study a random sample of inpatients was chosen to conduct this study within. The sample consisted of 450 inpatients. To determine the impact of Health Service Quality on Patient's satisfaction the researcher used a special measure called "SERVPERF" which was designed specially to measure the quality of service in different Service sectors the content validity of the measure conducted by committee arbitrators and throughout the multiple use of this measure over the time. The reliability of the measure computed using Cronbach alpha and the result indicated that the internal consistency of the measure was $90 \%$.

The result revealed that:

1) There is an Impact for the health service quality on patient's satisfaction.

2) There is a significant statistical difference of the Impact of Health Service quality on patient's satisfaction between Hospitals of public and private sector.

3) The Impact of health service quality on patient's satisfaction in private Hospitals sector is better than that in public Hospitals sector.

4) The responsiveness diminution of health service quality has the lowest mean out of other service quality diminutions in public and private sectors.

This study find out many recommendations as:

1) The hospital's administration in both public and private sector should to raise up the employee's qualifications to ward assimilation of the patients need and wants such as to tell them exactly when service will be performed, and to submit prompt service for the patients, and the employees should have the willing to help patients.

2) The Hospitals administrations should make periodic revision for the application each service quality divisions and their items in their Items in their Hospitals through the applying (SERVEPERF) measure and they should have to measure the patents satisfaction to mend any defect automation ally.

3) Hospital's administrations should put mechanisms to keep in touch with patients after discharge to hear from them about their Hospitals service and the extent of their satisfactions because the patients after discharge feet freely to say and criticize.
\end{abstract}


Keywords: Health service quality, Patients' satisfaction, Private and public hospitals, Jordan

\section{Introduction}

The health sector in Jordan characterized by providing quality and efficiency health services which made him a distinctive regional medical center (national health strategy 2006-2010). There is a strong orientation in medical institutions to develop a plan of action for the application of the quality concept, with the number of non-Jordanian patients treated with in Jordanian hospitals around 250,000 patients for 2008 where Jordan was ranked first among the Arab International in therapeutic tourism (private hospitals Association) (www.phajo.com, 2009) where patients receive a health service that meets the expectations of the satisfactory service.

The quality of health service and continuity to provide convenience for the patient are important elements of quality of service affecting the degree of satisfaction among patients, which affects patient trends towards these institutions therefore we find that Groonroos made the mental image of the client one of the components of quality of service (Groonroos, 2001) with a quick glance at the reality of the health services in Jordan, Jordan's population reached 5.350 .000 inhabitants, of whom $82 \%$ live in cities and the rest in rural and desert areas, $38 \%$ of the total population concentrated in the capital Amman, as $73 \%$ of the population of the Kingdom covered by health insurance coverage, including $31 \%$ who are subject to the civil health insurance, $26 \%$ are covered by military health insurance, $8.5 \%$ are covered by UNRWA , $1.3 \%$ are subject to the University Hospital and $6 \%$ were covered by private health insurance. (National health strategy, 2006-2010).

Therefore the health services to citizens are divided through 103 hospitals as the following: (30) belonging to the Ministry of health hospitals (public), (60) private sector hospitals and (11) hospital medical services tracking property (the military) and university hospitals where hospital comprises approximately 11,000 beds as well as medical centers, more than 671 centers spread over parts of the Kingdom from North to South at a rate of 1.2 health centre per 10,000 inhabitants and is in line with global averages (Ministry of Health, 2007).

The importance of this study lies in the fact that its dealing with the quality of health services in hospitals in the public and private sectors in relation to patient satisfaction through the application of Service Performance (SERVPERF) prepared to measure actual service quality perceived by patients and its effect on satisfaction. also the importance of this study lies in identifying the difference between the dimensions of quality of health service in public sector hospitals relative to private hospitals and their impact on patient satisfaction, researcher sees that this is a fundamental point in the importance of research as it can be considered as a case that can be distinguished from other such studies as a vital and sensitive topic addressed in the health services sector.

\section{Problem of the study}

The problem lies in determining the impact of health service quality on the consent of the beneficiaries in public and private hospitals in Jordan. To achieve this goal we must answer the following questions:

1) What is the impact of health service quality provided by public and private hospitals in Jordan on patient satisfaction?

2) What is the impact of health service quality provided by the public sector hospitals on patient satisfaction?

3) What is the impact of health service quality provided by the private sector hospitals on patient satisfaction?

4) Is there a difference between the quality of health service and patient satisfaction in private sector hospitals versus public sector hospitals?

\section{The study hypotheses}

In order to answer the questions above the following study hypotheses were formulated:

1) There was no statistical significant effect of the quality of health services provided by hospitals (private and public) on patient satisfaction.

2) There was no statistical significant effect of the quality of health service provided by public hospitals on patient satisfaction.

3) There was no statistical significant effect of the quality of health service provided by private hospitals on patient satisfaction.

4) No statistically significant differences between the health service quality and patient satisfaction in private sector hospitals against public sector hospitals.

\section{Study model}

Insert Figure 1 here 


\subsection{Study limitations}

This study was limited to hospitals in the private and public sectors confined within capital governorate for 2009 which offers comprehensive health service and increase the number of its beds is more than 120 , as it is the excluded specialized hospitals that provide specific service to patients as hospitals for childbirth, eye, psychological disorders, cancer as well as the military sector and to privacy.

\subsection{Conductive definitions}

The quality of health service: A health service that meets the needs and wishes of patients and provide them gently in time and eliminate symptoms

Tangibles: The appearance of touchable material objects by the patient such as medical tools and equipment, hospital appearance and exterior workers appearance ...

Reliability: The extent of reliance on the service provider's ability to deliver service accurately and as promised

Responsiveness: The desire level of providing service to the patient with the necessary speed and on-demand

Assurance: Knowledge and politeness of service providers and their ability to promote an atmosphere of trust and safety to the patient

Empathy: Personal care and attention provided by the hospital to the patient

Satisfaction: If the patient being pleasant or non pleasant after receiving the health service.

\section{Theoretical concept $\&$ previous studies}

\subsection{Service concept}

The service defined as "activity or benefit provided by one party to another and are basically intangible (not entailing of any ownership) and its production might be associated or not with a material commodity. (Kotler and Keller, 2006, P402).

5.1.1 Attributes and characteristics of the service

Al-Allaq \& Al-Tai identified (Al and Al-Alaq, 2009, p. 39) attributes and characteristics of the service as follows:

1) Intangibility

Means that it doesn't have a material and tangible recipient can judge through their known senses of smell or touch or taste, hearing and watching it prior to purchase and see the result precisely. Therefore, some offer the service through an attractive formula that gives intangiblety on the service.

2) Inseparability

Means to produce and consume the service at the same time, some services is considered for the consumer an integral part of the production of the service, and therefore the consumer of the service must be in the same location of the service production.

This also applies to the health service, where its presentation requires a recipient in the same place of production.

3) Variability

Here it means the inability to produce the same service every time, it is difficult to homogenize particular services that rely on human, and therefore difficult to maintain a certain quality level. For example, a surgery made on a patient has a success rate that varies from a doctor to another and also differs for the same physician from patient to another.

4) Perishability

The oscillation problem of service request, the demand for service is irregular, which gives the enterprise the opportunity to arrange their capacity and the size of the staff on this basis, but there is high demand periods that require significant capacity and staff, and there are periods of low demand where the large staff becomes an expensive burden on the Organization, that the work process in hospitals is fluctuating by seasons, social and general conditions of the people.

At a time when work is weak, you cannot store non-busy beds, disabled staff for peak workloads, therefore there is a lost profit opportunity in that period, and this requires good and sensitive management in order to balance between high and low demand seasons of service. 
Through the above \& dropping their service overall attributes to health service we find they also tended to be intangible, which cannot be discerned such as physical products and only judged by receiving, and cannot be owned by them. Its production is also at the same time as being received, thus the patient must be in the same location as the presence service, it cannot separate production from consumption, and the recipient is an integral part of their production, they are heterogeneous with differing service provider and receiver, also it cannot be stored.

\subsection{Quality concepts}

We note that the idea of quality means excellence, clear standards and higher performance, quality factor can be measured, and the role of quality come in achieving (Competitive Advantage) to the concerned institution, quality of health service is applied by medical science and technology in a manner to achieve the fullest possible public health without increasing risk, thus quality is determined by the best possible balance between risks and benefits. (Niaz, 2007, page 50).

\subsubsection{Quality types}

Gronroos determined (Gronroos, 2001) quality types as follows:

1) Technical Quality

A service that is received by the client as a result of a process of interaction with the institutions providing the service or in other words, is the final benefit accruing to the recipient of the service and expressed in the question what has been submitted?

\section{2) Functional Quality}

A method or a way of how the output is transferred to the beneficiary from the service and expressed in the question how is the service submitted?

3) Mental impression on the organization

The image of the organization or institution in the mind of the customer or the customer's impression of what is a service organization and this dimension is the inevitable outcome of the technical and functional dimensions of quality and evaluation of clients. (Gronroors, 2001) as (babakus, 1992) on health service quality components as follows:

1) The technical quality of the health service:

Means the accuracy of diagnostic and treatment procedures are difficult to judge by the recipient of the service.

2) Functional quality of health service:

How to provide health service for patients, this aspect of service could be understood and judged by the receivers on the quality of health service.

\subsection{Service quality measurements}

There are two methods of measuring quality of service one attributed to Parasurman et al (1985), and based on customer expectations of service level and understanding of the level of service already provided, and then selecting the gap (or match) between these expectations and perceptions using quality of service five dimensions of which are intangibility, reliability, responsiveness, empathy, and certainty. This method of service quality measurement was called measurement gap or SERVQUAL scale, the centerpiece in service quality measurement model is the gap between the perception of the actual performance level of client service and his expectations about the quality of this service. But this gap depends on the nature of the gaps related to design, market and delivery of the service. There are five fundamental gaps:

Gap No. (1): results from the difference between customer expectations of the service level and management understanding of customer expectations, in other words the administration's inability to know the needs and wishes of customers.

Gap No. (2): it results from the difference between service specifications already delivered and the perceptions of client's expectations, Means that even if the customer needs and desires are expected from the management, it will not be translated into the expected specifications due to restrictions concerning the resources of the organization, or the inability to embrace the philosophy of quality management.

Gap No. (3): it emerges because the specifications of the service actually provided do not match what the Department recognizes regarding these specifications. This may be due to the low level of skilled employees responsible of the service, which in turn is due to the lack of capacity and willingness of workers. 
Gap No. (4): it results from unbalanced connection between the Organization \& its customers, in the sense that the promises made by the Organization on the level of service through customer contact (personal sales and other promotional efforts) differs from the level of service provided and its actual specifications.

Gap No. (5): perceptions and expectations gap by customers, quality of service as perceived by clients depend on the amount and direction of this gap and that depend on the nature of previous gaps where this measure has been applied to a variety of services, including banking, air transportation, education, fast food, health service, engineering service, advisory, dry cleaning service and others.

The second method to measure the quality of service (Cronin, Taylor, 1992) focuses on measuring the actual performance of the service provided to the customer based on that the quality of service is expressed as a kind of trends and this method in measuring quality of service is called actual performance measure or SERVPERF. The new method did not differ in dimensions used in the measurement of service quality of tangible aspects, reliability, responsiveness, certainty and empathy. As seen by the founders of this scale it is distinct from earlier by simplicity and ease of use, as well as a higher degree of credibility and realism because it excludes subtractions between customer expectations and his service level perceptions.

\subsection{Clients satisfaction concept (patients)}

(Zeithmal, etal, 2006, P110) Defined satisfaction as the (evaluation of customers on a service or product \& does it fulfill their needs and expectations).

(Zeithmal, etal, 2006, pp.110-116) Identified factors influencing satisfaction:

* Service profiles and properties: satisfaction is influenced by the extent to which customer perception of service profiling and benchmarking.

* Client emotions: personal emotional factors affecting customer satisfaction, such factors as emotions and sentiments of those clients which have been found to affect the satisfaction.

* Sense of equality and justice: where the customer will usually ask the same question: was I fairly treated like other clients?

* Quality: customers' perception of quality dimensions affects satisfaction.

* Conditional factors: which the client has no ability to control such as weather and traffic and the characteristics of the service provider, such as: size of enterprise, the number of employees and geographical location.

Relatives: the client view is influenced by family members, co-workers and friends.

\subsection{Satisfaction measurement}

Korler and Keller (Korler and Keller, 2006 p145) see that customer satisfaction can be measured by many ways:-

1) Customer interview and especially through sales representatives and by being asked directly.

2) Periodic surveillance: through the distribution of questionnaires or via websites

3) Secret client: one of the members of the Administration to disguise as a customer and ask customer's questions on their satisfaction and identifies the degree of satisfaction.

\subsection{Previous studies}

1) Study of (Abu Musa, 2000) entitled: "impact of service quality on customer satisfaction and profitability in Jordanian banks" (a comparative study between the Housing Bank and Islamic Jordanian Bank). Aimed at identifying quality banking services actually provided in each of the Housing Bank and the Jordan Islamic Bank, and also aimed to link the relationship between Bank service quality and profitability increase represented at the rate of return on investment, three questionnaires were distributed: one for clients, and another for staff, and another for directors, including a sample of 112 Directors (148) from banks, (602) for banks' clients. Where the study concluded:

The need for each of the Housing Bank and the Jordan Islamic Bank to design strategies and policies in order to improve the quality of the service actually provided by the Bank through the development of intangible aspects, showing interest and personal knowledge of customers, in addition to working to improve mental impression of quality banking service actually provided, through intensified promotion of personal communication with customers and conduct more market research to determine the causes of the gap between the management's perception of banking service quality actually provided and customers' perception of banking service quality.

2) (Shkukani, 2003) study entitled: "impact of perceived quality on profitability and growth" (a comparative study between the sectors of commercial banks and private hospitals in Jordan of applying the model of service 
and profitability series) the aim of this study is to test the impact of perceived quality on profitability and growth in the Jordanian services institutions, where the study was based on classified sampling of the study community (1000) individuals from customers and (500) individual from staff. The study concluded: the need to increase the interest of private hospital departments and commercial banks to provide a comfortable working environment for staff and improve various aspects of the Interior quality in particular concerning respect and appreciation of staff, developing their skills, increasing the level of participation ,raise morale, increase the assurance on examining the needs of customers and pinpoint, increase attention to the front line staff in the services organizations and upgrade their skills and abilities in dealing with customers.

3) (Aladham, 2004) study entitled "identifying perceived service quality health in Palestinian hospitals" study aimed to explore the possibility of applying quality management in health care system through the identification of the already applicable and perceived service level in Nablus public, private and charitable hospitals. A questionnaire has been built on a sample of employees and patients. Total sample size was (650) questionnaires, (150) distributed on patients and (500) on staff and departments of the hospitals. The study concluded that the majority of Nablus hospitals did not have a workable system that identifies all types of actions imposed in this direction, this study showed different trends and differences by care and service recipients to contribute to understanding and identifying the receive process for the service and the study indicates a direct relationship in all hospitals between service procedures and patient satisfaction. Also, staff attitudes and values are not only linked with patient satisfaction, but have a direct impact on all the activities of the hospital.

4) (Shahin, 2006) Study entitled: "Servqaul and Model of Services Quality Gaps" this study took place in Iran in some food companies and the study sample consisted of 52 customer from the customers of these companies where the study was designed to use SERVQVAL scale for measuring quality of service through identifying gaps between customer expectations and actual service rendered to him also it aims to help manage and improve quality in identifying important dimensions of quality and identify priorities in improving quality and reducing the gap, The study indicated that the measure of SERVQVAL is widely used in external service quality measurement of the external client and this standard can also be formed to measure the quality of the Interior quality between the sections and units within the institution.

\subsection{What distinguishes this study from earlier studies}

Through a review of previous studies, this study can be distinguished from others that it will study the actual performance of the health service's perceived by patients in Jordanian hospitals and linking it to their level of satisfaction and with the researcher's knowledge this study will be the first of its kind in Jordan in this area using this scale where quality information will be provided on the extent of application of the Jordanian hospital to the health service dimensions so that the managements of hospitals can measure health service quality and to raise it to the expectations of patients, which Lead to complacency.

Most previous studies conducted in the measurement of service quality and customer satisfaction at the various sectors, including services of financial institutions and services of hotels, restaurants and others did not address the quality of health services, but few of them in some of the world either in Jordan have yet to record any study in this area as within the knowledge of the researcher until this moment.

\section{Method \& procedures}

Community study: all hospitals in the public and private sectors in the Hashemite Kingdom of Jordan which are 103 according to the records of the Ministry of health hospitals are distributed according to table (1).

\subsection{Study sample}

The study sample was confined to hospital patients in public and private sectors in the capital city of Amman which contains most of the disciplines most types of health service, and classified the concept of the Ministry of health (NHS) hospital patients were taking over the number of families on 120 beds is illustrated in table (2)

For the sample size the sample number was selected based on the following equation:

$$
\mathrm{N}=\frac{\mathrm{z}^{2} \mathrm{p}(1-\mathrm{p})}{}
$$

$$
\mathrm{E}^{2}
$$

$\mathrm{N}=$ Sample size

$\mathrm{Z}=1.96$

Confidence level $95 \%$ when the error margin is 5\%

$\mathrm{E}=\mathrm{MARGIN}$ OF ERROR $=5 \%$ 
By Compensation

$$
\begin{aligned}
\mathrm{N} & =\frac{(1.96)^{2}(.5)(1-.5)}{(.05)^{2}} \\
& =384 \text { individuals }
\end{aligned}
$$

As a precaution a sample of 450 patients were taken \& distributed over the relevant hospitals relatively to the number of beds as shown in the preceding table (Law No. 3-1). The sample was selected from patients in hospitals by classified random way.

\subsection{Study collecting tool}

To achieve the objectives of the study and test specified hypotheses of the study which was requested by gathering information from primary and secondary sources:

a- Secondary data have been used from textbooks and scientific references, plus research and thesis in addition to periodicals and official statistics.

b- Primary data: it has been collected through field study using questionnaires designed to achieve the objectives of the study these questionnaires consist of three parts:

Part I: information gathering included demographic study sample vocabulary (such as gender, age, monthly income, health insurance, social status, academic qualification, education level and the country).

Part II: included twenty sentences represent the five major dimensions of health service quality SERVPERF scale for measuring the actual performance of the health quality of service provided to patients across the dimensions of quality of service as follows:

- $\quad$ Intangibility was measured by paragraphs (1-4)

- $\quad$ Reliability was measured by the paras (5-8)

- $\quad$ Response was measured by the paras (9-12)

- $\quad$ Assurance was measured by paragraphs (13-16)

- $\quad$ Empathy was measured by paragraphs (17-20)

Part III and included only one question to determine overall satisfaction with the quality of health service.

\subsection{Hypothesis test}

Covers the researcher in this section test the study hypotheses, using appropriate statistical method, which had been formulated on the basis of the problem of study and questions, as follows:

H0-1: There was no statistical significant effect on the quality of health service provided by public and private hospitals on patient satisfaction.

In order to test this hypothesis a variance analysis for regression was made to measure the relationship between quality health service provided by hospitals and patient satisfaction, and the results were presented in two groups: Group 1:

The table (3) shows the results of analysis of variance for regression to measure the impact of health service quality relationship between hospitals and patient satisfaction

The table (3) shows a significant statistical impact at the level of significance $(\alpha<0.05)$ health service quality provided by public and private hospitals and patient satisfaction, where value (F) increased as calculated as (138.038), which is larger than value (F) tabular amounting (3.860) and the level of significance $(0,000)=$ $\mathrm{P}$-value which is smaller than $(\alpha<0.05)$.

Multiple regression analysis was made to find the estimated value $\left(\mathrm{B}^{\wedge}\right)$ to measure the impact of health service quality in hospitals, patient satisfaction and table no. (4) shows the results of the analysis.

The previous table indicates that the value of the (BETA) for tangibility (0.056), and (0.047) for reliability $(0.080)$ to response and (0.094) for assurance, and (0.043) for sympathy, they are statistically function values at the level of significance $(0.05)$ where calculated $(\mathrm{t})$ values are higher from indexed value $(\mathrm{t})$, demonstrating that health service quality provided by public and private hospitals have an impact on patient satisfaction, and the value of the coefficient of determination (R2) reached (0.601) indicating that the quality of health service provided by public and private hospitals in The regression model to explains what $(0.601)$ in the variation of the dependent variable of patient satisfaction. This results in rejection of the fourth null subsidiary hypothesis which 
conscripts of: no statistically significant relationship between the quality of health service provided by public and private hospitals and patient satisfaction.

H0-2: There was no statistical significant effect on the quality of health service provided by public hospitals on patient satisfaction.

To test this hypothesis a variance analysis for regression was made to measure the relationship between health service quality provided by public hospitals and patient satisfaction, and the results were presented in two groups: Group 1. This group displays the results of the analysis of the relationship of health service quality provided by the hospitals in the public sector and patient satisfaction.

Table (5) shows the results of variance analysis for regression to measure the impact of the relationship between health service quality provided by the public sector hospitals and patient satisfaction

table (5) shows a significant impact at the level of statistical significance $(\alpha<0.05)$ of quality health service provided by public hospitals and patient satisfaction, where a high value of $(\mathrm{F})$ calculated as (69.79) is greater than the value $(\mathrm{F})$ tabular which reached (3.860) and the level of significance $(0,000)=\mathrm{P}$-value is smaller than $(\alpha$ $<0.05)$.

Multiple linear regression analysis was made to find the estimated value $\left(\mathrm{B}^{\wedge}\right)$ to measure the relation impact of health service quality provided by the public sector hospitals and patient satisfaction, table (6) shows the results of the analysis.

The previous table indicates that the value of the (BETA) for tangibility $(0.056)$, and $(0.051)$ for reliability and $(0.087)$ for response and $(0.073)$ for assurance, and (0.042) for sympathy and they are statistically function values at the level of significance $(0.05)$ where $(\mathrm{t})$ calculated values are higher from indexed ( $\mathrm{t}$ ) value, demonstrating that quality health service provided by public hospitals have an impact on patient satisfaction, and the value of the coefficient of determination (R2) reached (0.55) indicating that the quality of health service provided by the hospitals in the public sector In the regression model explains what $(0.55)$ variation in the dependent variable of patient satisfaction. This results in rejection of the first subsidiary null hypothesis, which conscripts of: no statistically significant relationship between the qualities of health service provided by public hospitals and patient satisfaction.

H0-3: No statistically significant relationship between the health service quality provided by private hospitals on patient satisfaction.

To test this hypothesis a variance analysis for regression was made to measure the relationship quality health service provided by private hospitals and patient satisfaction, and the results were presented in two groups: Group 1: This group displays the results of the analysis of the relationship of health service quality provided by private hospitals and patient satisfaction.

The table shows (7) the analysis of variance results for regression to measure the impact of health service quality of private hospitals and patient satisfaction.

Table (7) shows there is an impact of statistically significant at the level of significance $(\alpha<0.05)$ of health service quality provided by private hospitals and patient satisfaction, where an increase of calculated value (F) of (42.601), which is larger than value (F) scheduled reaching $(2.27)$ and the level of significance $(0,000)=\mathrm{P}$-value which is smaller than $(\alpha<0.05)$.

Multiple regression analysis was made to find the estimated value $\left(\mathrm{B}^{\wedge}\right)$ to measure the impact of health service quality provided by private hospitals and patient satisfaction and table (8) shows the results of the analysis.

The previous table indicates that the value of the (BETA) to tangibility reached $(0.060)$, and $(-0.004)$ for reliability and (0.047) for response, (0.094) for assurance and (0.093) for sympathy and is statistically function values at the level of significance $(0.05)$ except after reliability where calculated $(t)$ values were larger from indexed value $(\mathrm{t})$, proofing that quality health service provided by private hospitals have an impact on patient satisfaction, and the value of the coefficient of determination (R2) reached (0.59) indicating that the quality of health services provided by hospitals In the private sector in the regression model except after reliability interprets (0.59) variation in the dependent variable of patient satisfaction. This results in rejection of the first null subsidiary hypothesis, which states that: no statistically significant relationship between the quality of health service provided by private hospitals and patient satisfaction.

H0-4: No statistical significant differences between the quality of health service and patient satisfaction in private sector hospitals as public sector hospitals taken as a measurement. 
The (T) test in Table (9) indicates to the existence of statistical significance differences at the level $(\alpha<0.05)$ of health service quality \& patient satisfaction between private hospitals measured on public sector hospitals, based on the calculated $(t)$ value which reached (4.352) and with significance level $(0.000)$ for tangibility and $(9.551)$ for reliability with significance level $(0.000)$, response (7.469) with significance level $(0.000)$, assurance $(9.685)$ with significance level (0.000), empathy (5.189) with significance level $(0.000)$, those are statistically significant values at significance level (0.05) the difference was in favor of private sector hospitals in all dimensions, as a reason of their high arithmetic means which are higher than those of the public sector hospitals, this results in the refusal of the third null subsidiary hypothesis which states: there are no statistical significant differences between health service quality \& patient satisfaction in private sector hospitals in relative to private sector hospitals.

\section{Results \& recommendations discussion}

1) The study proved that there is an impact of health service quality provided by hospitals on patient satisfaction through multiple review analysis results. Where the results showed that calculated $(t)$ values from indexed values (t) as well as study (shaihr, etal, 2008) which emerged that there is a gradual rise in patient satisfaction that increases with the process of improving the health service.

In addition to the study (Abu Jalil, 2007) and a study (Abu Musa, 2000) and a study (Abbadi, 2007), all of which confirmed the existence of a relationship between the quality of service provided to clients and their satisfaction.

2) The study showed that there were statistically significant differences in the impact of health service quality on patient satisfaction in private sector hospitals against public sector hospitals in favor of private sector hospitals as shown through the results that averages of the five quality dimensions in private hospitals is higher than the average dimensions of quality in public sector hospitals. This is due mostly to the processes of development, modernization and keep up with all new medical fields by private hospitals, so it can continue to resist the fierce competition in the markets of the health sector, we find that the private sector hospitals are constantly trying to provide unique health service because it affects the profitability of these institutions and continuity. As for the public sector hospitals which are less sophisticated in practice than the private sector hospitals because of bureaucracy and overcrowding and long lines and long waiting process made its classification of level quality of service less than private sector hospitals. This result is consistent with the findings of the study of (Jungki, lee, 2005), where the study attributed the causes of low levels of quality of health service in public hospitals to the number of reviewers pressure, and the patient does not have the option of choosing the hospital but by place of residence as well as the study of (Nazalee.S, and, shahjahan.A.,2007), which concluded that the quality of health service provided to patients in private hospitals is better than the service provided by the public sector hospitals in Bangladesh.

3) The study showed that response dimension containing paragraphs, online patient service deadline to respond to their needs and provide the service to him instantly, as well as permanent desire among staff in providing service to the patient has received the lowest arithmetic mean between dimensions of quality of service in public sector hospitals and this also seems to be caused by the lack of training and experience of hospital personnel in dealing with the requirements of patients where this reflects the capacity of staff to apply the principle of orientation towards the client (Customer oriented) so that they remain a ready and willing staff To meet the requirements of the patient and this requires the departments of the hospitals to focus on this aspect of quality of service (response) to upgrade the performance of service by attracting talent and improve working staff by improving higher salaries in the health field.

4) It was noted that the assurance has the top of arithmetic means and this dimension contains a sense of security to the patient while receiving service and that hospital workers have the sufficient knowledge, and the decent dealing with the patient which boosts confidence.

This is due to the high level of medical service in private sector hospitals and its possession of distinguished doctors in addition to expertise.

5) Private hospitals mostly acquired an arithmetic mean not far from the high report as noted in tangibility where the arithmetic mean was estimated 3.62 with an average report, the arithmetic mean of the high report is estimated 3.67 and this is due to processes of modernization and development in public sector hospitals recently made.

\section{Recommendations}

1) Continue to work hard by those responsible for public sector hospitals in upgrading the quality of health service and continue the process of development and modernization, especially in the area training of human resources and upgrading of staff. 
2) Upgrading health personnel and especially focus on response dimension, one of the important dimensions of quality of service which directly fulfill the requirements of the patient.

3) The need for action by the departments of hospitals to review quality dimensions by applications of quality measurements periodically during close periods and control levels of quality and patient satisfaction levels and modify errors to maintain sustainable health quality.

4) As well as the departments of hospitals to develop a mechanism to communicate with patients and surveyed after their service is completed and returning to home and because some patients conceal feelings and opinions, especially if they express dissatisfaction, fearing abuse by medical and nursing personnel at hospitals \& that achieves two benefits:

a) See the real situation of quality of service provided.

b) Also, in the event of consent by the patient satisfaction, it creates depth and in the absence of consent to mitigate the impact of discontent and identifies the areas of deficiency in service which reflects the mental image of the hospital and mitigate the impact of the low level of service.

\section{References}

Abbadi, Ahmad Abd Al-Haj Mohamed. (2007). An analytical study: impact of the application of TQM on customer satisfaction in the Jordanian pharmaceutical manufacturing factories. Arab Amman University for graduate studies Amman, Jordan.

Abu Jalil, Mohamed. (2007). Jordanian industrial corporations' satisfaction on the quality of consultation offices operating in Jordan. MPhil, Arab Amman University for graduate studies, Amman, Jordan.

Abu Musa, \& Rasmyieh Ahmed Amin (2000). The impact of service quality on customer satisfaction and profitability in Jordanian banks: a comparative study between the Housing Bank and the Islamic Jordanian Bank. MPhil, Al al-Bayt University, Jordan.

Akhdair, Noha Adel. (1994). The concept of quality in health services, the Jordanian Ministry of health in cooperation with the United States Agency for international development. Amman, Jordan.

Aladham, majd Abdul Rahman Fred. (2004). Determine the quality of service perceived health in Palestinian hospitals. MPhil, Najah University, Palestine.

Al-Mudhaf, buthaina. (2007). Program quality in the health sector in the State of Kuwait, the quick Gulf Forum for quality. Kuwait.

Al-Tai, Hamid and Al-Alaq, Bashir. (2009). Marketing services, strategic Dimension. Amman: Dar alyazuri.

Babakus, Emin, and Mangold W. Glynn (1992). Adapting the Servqual, Scale to Hospital Services: An Empirical Investigation. Health Services Research, Vol. 26, No. 6, pp. $765-786$.

Berenson Mark L., Levine David M., and Krehbiel Timothy C. (2006). Basic Business Statistics, concepts and applications (3rd Edition). P. 278.

Bolton, R. N., and J. H. Drew. (1993). Multistage Model of Customer, Assessment of Service Quality and Value. Journal of Consumer Research, Vol.17, P. 75-84.

Cronin, J., and Taylor, S. (1992). Measuring serricc quality. Are-examination and Extension. Journal of marketing, 56 (July), PP.55-68.

Eltehewy, Maha, quality health care (where we are now), Faculty of medicine, Program performance simulation, University of Ain Shams, Egypt.

Gronroos, C. (2001). A service quality model and it's marketing Implications. European Journal of marketing, 18 (4), PP. 36-44.

Haksik Lee, Yong Kilee and Dongkenn Yoo (2000). The Determinants of Perceived Services Quality and its Relationship Satisfaction. Journal of Services Marketing, Vol. 14, No. 3, pp. 217-231.

Idris, Thabit Abdul Rahman (1996). Measuring quality of service by using the gap between the perceptions and expectations, study methodology applied to health workers in the State of Kuwait. Arab Journal of administrative, folder 4, number 1 (pp. 9-35).

Idris, Thabit and Morsi, Jamal (1993). The service quality measurement and analysis of the relationship between both satisfaction and propensity and tendency to purchase. Journal of trade and finance, Faculty of Commerce University of Tanta, Egypt. 
Jungki Lee (2005). Measuring Service Quality in a Medical Setting in a Developing Country: The Applicability of Servqual. Services Marketing Quarterly, Vol. 27 (2). http://dx.doi.org/10.1300/J396v27n02_01

Khshim, Mohammed. The conflict of the quality of medical care and health insurance system application, Jeddah.

Kotler, P., and Keller, K.L. (2006). Marketing management. (12th Edition). New Jersey, Pearson: Prentice Hall.

Lehtinen, J.R., and Lehtinen (1982). Service Quality: a Study of Quality Dimensions. Service Management Institute, Helsinki, unpublished working paper.

Lisa J. Morrison Coulthard (2004). Measuring Service Quality A review and critique of research using Servqual. International Journal of Market Research, Vol. 46, Quarter 4, pp. 479 - 498.

Lovelock, C., Wirtz, J., Chew, P. (2009). Essentials of service marketing. Singapore. Pearson: prentice Hall.

Ministry of Health (2007). Annual Statistical Book. Amman, Jordan.

Mohammed Ali, Hussam (2007). The impact of the use of domestic marketing for the quality of services provided to customers (patients and reviewers) in Arab Medical Center (field study). MPhil, Arab Amman University for graduate studies Amman, Jordan.

Myerscough Mark. (2002). Concerns about Servqual's Underlying Dimensions. Illinois State University.

Niaz, Abdul Aziz Habib Allah (2007). Health care quality theoretical foundations and practical application. the Ministry of health, Saudi Arabia.

Parasurman A., Zeithaml V.A., and Berry L.L. (1996). The Behavieral Consequences of Service Quality. Journal of marketing, Vol.60, pp. 31-46. http://dx.doi.org/10.2307/1251929

Parasurman A., Zeithaml V.A., and Berry, L.L. (1988). SERVQUA1:A Multiple-item Scale for Measuring Consumer Perceptions of Service Quality. Journal of retailing, VOL. 64, No. 1, pp. 12-40. .

Parasurman, A., Zeithaml, V.A., and Berry, L.L. (1985). Aconceptual Model of service Quality and its implication for future research. Journal of marketing, 49(Fall), PP41-50.

Sanjak, Ghalib (2010). The International Committee for hospitals between theory and practice in a comprehensive study of the reality of the Jordanian hospital. Amman, Jordan, Dar al-elam for publication and distribution.

Series of legal and economic sciences (2005). The marketing of health services in hospitals, Tishreen University. Journal of scientific studies and research, Lathakia, Vol. 27, No. (2), Syria.

Shahin, Arash (2006). "Servqaul and Model of Services Quality Gaps, A Framework for Detmining and Prioritizing Critical Factors in delivering Quality Services" in Service Quality - An Introduction (1st Edition). Partha Sarathy, pp. 117-131.

Shaikh, B.T., Mobeen, N., Azam, S.Z., \& Rabbani, F. (2008). Using Servqual for Assessing and Improving Patient Satisfaction at a Rural Health Facility in Pakistan. Mediterranean Health Journal, Vol. 14, No. 2.

Shkukani, Mounir (2003). The perceived quality impact on profitability and growth. MPhil, Arab Amman University for graduate studies, Amman, Jordan.

Siddiqui, N., \& Khandakar, A.K. (2007). Comparison of Services of Public, Perivale foreign Hospital from the Perspective of Bangladesh Patients. Journal of Health population and Nutrition, vol.25, No.2, pp. 221-230.

Teas, R, Kenneth (1993). Expectations, Performance Evaluation, and Consumers Perceptions of Quality. Journal of marketing, VOL. 57 (4 ), p. 8. http://dx.doi.org/10.2307/1252216

Zaroor, Grace (2003). The impact of quality and price of services provided by banks to their clients ' satisfaction of the industrial sector in Jordan. MPhil, Arab Amman University for graduate studies Amman, Jordan.

Zeithaml V.A., Berry L.L., and Parasuraman A. (1988). Communication and Control Process in the Delivery of Service Quality. Journal of Marketing, VOL. 52, No. 2, pp. 35 - 48. http://dx.doi.org/10.2307/1251263

Zimeras,S., Kostgiolas, P., and Lambrinoudakis, C. (2007). Quality Evaluation in Healthcare Based on the Assessment of Services Expectation. The Journal on Information Technology in healthcare, vol. 5(1), pp. 50 58.

www.pha_jo.com 
Table 1. Hospitals distribution on medical sectors

\begin{tabular}{|l|c|c|}
\hline Medical sector & Hospitals No. & No. of beds \\
\hline Ministry of health & 30 & 4250 \\
\hline Medical services & 11 & 2131 \\
\hline Jordanian university & 1 & 531 \\
\hline The establishing king hospital & 1 & 489 \\
\hline Private sector & 60 & 3642 \\
\hline total & 103 & 11043 \\
\hline
\end{tabular}

*Ministry of Health, 2007

Table 2. Sample study's hospitals

\begin{tabular}{|l|l|c|c|c|c|c|}
\hline No. & Hospital name & specialty & sector & $\begin{array}{c}\text { No. of } \\
\text { beds }\end{array}$ & $\begin{array}{c}\text { Sample } \\
\text { individual no. }\end{array}$ & percentage \\
\hline 1 & Al-basheer & general & general & 928 & 137 & 30.4 \\
\hline 2 & Prince Hamza & general & general & 402 & 59 & 13.1 \\
\hline 3 & $\begin{array}{l}\text { Dr. Jameel } \\
\text { Totanji }\end{array}$ & general & general & 129 & 19 & 4.2 \\
\hline 4 & $\begin{array}{l}\text { Jordanian } \\
\text { university }\end{array}$ & general & general & 535 & 79 & 17.6 \\
\hline 5 & Jordan & general & private & 252 & 37 & 8.2 \\
\hline 6 & Islamic & general & private & 237 & 35 & 5.1 \\
\hline 7 & Al-KhalidI & general & private & 160 & 23 & 4.9 \\
\hline 8 & Al-IstiqlaL & general & private & 144 & 22 & 4.7 \\
\hline 9 & Al-Takhasosi & general & private & 140 & 21 & 4.0 \\
\hline 10 & Al-Israa & general & private & 125 & 18 & 100 \\
\hline
\end{tabular}

Table 3. The results of variance analysis of regression for the effect of health service quality provided by hospitals and patient satisfaction

\begin{tabular}{|l|l|c|c|c|c|c|c|}
\hline Independent & Variation & $\begin{array}{c}\text { Squares } \\
\text { total }\end{array}$ & $\begin{array}{c}\text { Degrees } \\
\text { of } \\
\text { Freedom }\end{array}$ & $\begin{array}{c}\text { Squares } \\
\text { mean }\end{array}$ & Calculated f & $\begin{array}{c}\text { Significa } \\
\text { nce }\end{array}$ & $\begin{array}{c}\text { Scheduled } \\
\text { f value }\end{array}$ \\
\hline $\begin{array}{l}\text { Health service } \\
\text { quality rendered } \\
\text { from public \& } \\
\text { private sector }\end{array}$ & Eegression & 347.057 & 5 & 69.411 & 138.038 & 0.000 & 3.860 \\
\cline { 2 - 8 } & Total & 223.263 & 444 & .503 & & & \\
\hline
\end{tabular}


Table 4. The results of multiple linear regression analysis of the impact of health service quality provided by hospitals and patient satisfaction

\begin{tabular}{|c|c|c|c|c|c|c|}
\hline Variable & Beta & $\begin{array}{l}\text { Standard } \\
\text { deviation }\end{array}$ & Calculated T & Scheduele T & $\begin{array}{l}\text { Degree of } \\
\text { significance }\end{array}$ & $\mathrm{R}$ square \\
\hline fixed & $0.808-$ & 0.175 & -4.614 & \multirow{6}{*}{1.960} & 0.000 & \multirow{6}{*}{0.609} \\
\hline Tangibility & 0.056 & 0.043 & 5.173 & & 0.000 & \\
\hline reliability & 0.047 & 0.047 & 4.004 & & 0.000 & \\
\hline response & 0.080 & 0.047 & 6.886 & & 0.000 & \\
\hline assurance & 0.074 & 0.045 & 6.520 & & 0.000 & \\
\hline empathy & 0.043 & 0.040 & 4.327 & & 0.000 & \\
\hline
\end{tabular}

Table 5. The results of variance analysis of regression for the effect of health service quality provided by public hospitals and patient satisfaction

\begin{tabular}{|l|l|c|c|c|c|c|c|}
\hline $\begin{array}{l}\text { Independent } \\
\text { variable }\end{array}$ & Variation & $\begin{array}{c}\text { Squares } \\
\text { total }\end{array}$ & $\begin{array}{c}\text { Degrees of } \\
\text { Freedom }\end{array}$ & $\begin{array}{c}\text { Squares } \\
\text { mean }\end{array}$ & $\begin{array}{c}\text { Calculated } \\
\mathrm{f}\end{array}$ & Significance & $\begin{array}{c}\text { Scheduled } \\
\text { f value }\end{array}$ \\
\hline $\begin{array}{l}\text { Health service } \\
\text { quality rendered } \\
\text { from public } \\
\text { sector }\end{array}$ & Regression & 202.255 & 5 & 40.451 & 69.79 & 0.000 & 2.25 \\
\cline { 2 - 8 } & Error & 166.929 & 288 & 0.58 & & & \\
\cline { 2 - 8 } & Total & 369.184 & 293 & & & & \\
\hline
\end{tabular}

Table 6 . The results of multiple linear regression analysis of the impact of health service quality provided by the public sector hospitals and patient satisfaction

\begin{tabular}{|c|c|c|c|c|c|c|}
\hline Variable & Beta & $\begin{array}{l}\text { Standard } \\
\text { deviation }\end{array}$ & $\begin{array}{c}\text { Calculated } \\
\mathrm{T}\end{array}$ & $\begin{array}{c}\text { Scheduled } \\
\mathrm{T}\end{array}$ & Significance & $\mathrm{R}$ square \\
\hline fixed & $0.937-$ & 0.234 & $-3.996-$ & \multirow{6}{*}{1.960} & 0.000 & \multirow{6}{*}{0.55} \\
\hline Tangibility & 0.056 & 0.050 & 4.529 & & 0.000 & \\
\hline reliability & 0.051 & 0.055 & 3.650 & & 0.000 & \\
\hline response & 0.087 & 0.056 & 6.212 & & 0.000 & \\
\hline assurance & 0.073 & 0.053 & 5.536 & & 0.000 & \\
\hline empathy & 0.042 & 0.046 & 3.634 & & 0.000 & \\
\hline
\end{tabular}


Table 7. The results of variance analysis of regression for the effect of health service quality provided by private hospitals and patient satisfaction

\begin{tabular}{|l|l|c|c|c|c|c|c|}
\hline $\begin{array}{l}\text { Independent } \\
\text { variable }\end{array}$ & Variation & $\begin{array}{c}\text { Squares } \\
\text { total }\end{array}$ & $\begin{array}{c}\text { Degrees of } \\
\text { Freedom }\end{array}$ & $\begin{array}{c}\text { Squares } \\
\text { mean }\end{array}$ & $\begin{array}{c}\text { Calculated } \\
\mathrm{f}\end{array}$ & Significance & $\begin{array}{c}\text { Scheduled f } \\
\text { value }\end{array}$ \\
\hline $\begin{array}{l}\text { Health service } \\
\text { quality } \\
\text { rendered from } \\
\text { public sector }\end{array}$ & Regression & 74.566 & 5 & 14.913 & 42.601 & 0.000 & 2.27 \\
\cline { 2 - 8 } & Error & 52.511 & 150 & 0.35 & & & \\
\cline { 2 - 8 } & 127.077 & 155 & & & & \\
\hline
\end{tabular}

Table 8. The results of multiple linear regression analysis to demonstrate the impact of health service quality provided by private hospitals and patient satisfaction

\begin{tabular}{|c|c|c|c|c|c|c|}
\hline Variable & Beta & $\begin{array}{l}\text { Standard } \\
\text { deviation }\end{array}$ & $\begin{array}{c}\text { Calculated } \\
\mathrm{T}\end{array}$ & Scheduled T & $\begin{array}{c}\text { Degree of } \\
\text { significance }\end{array}$ & $\mathrm{R}$ square \\
\hline fixed & -0.265 & 0.33 & $0.802-$ & \multirow{6}{*}{1.960} & 0.424 & \multirow{6}{*}{0.59} \\
\hline Tangibility & 0.060 & 0.103 & 2.306 & & 0.022 & \\
\hline reliability & -0.004 & 0.121 & 0.118 & & 0.906 & \\
\hline response & 0.047 & 0.095 & 2.004 & & 0.047 & \\
\hline assurance & 0.074 & 0.14 & 2.108 & & 0.037 & \\
\hline empathy & 0.093 & 0.109 & 3.406 & & 0.001 & \\
\hline
\end{tabular}

Table 9. Arithmetic means, standard deviations and the results of the "T" test to the differences between private sector hospitals against public sector hospitals in health service quality and patient satisfaction

\begin{tabular}{|c|c|c|c|c|c|c|c|}
\hline Dimension & Hospital & No. & $\begin{array}{c}\text { Arithmetical } \\
\text { mean }\end{array}$ & $\begin{array}{l}\text { Standard } \\
\text { deviation }\end{array}$ & $\begin{array}{c}\text { Standard } \\
\text { error }\end{array}$ & $\begin{array}{c}\text { Calculated } \\
\mathrm{T} \text { value } \\
\end{array}$ & Significance \\
\hline \multirow[t]{2}{*}{ Tangibility } & private & 156 & 4.01 & 0.659 & 0.053 & \multirow{2}{*}{4.352} & \multirow{2}{*}{0.000} \\
\hline & Public & 294 & 3.62 & 1.013 & 0.059 & & \\
\hline \multirow[t]{2}{*}{ Reliability } & private & 156 & 4.13 & 0.694 & 0.056 & \multirow{2}{*}{9.551} & \multirow{2}{*}{0.000} \\
\hline & Public & 294 & 3.30 & 0.955 & 0.056 & & \\
\hline \multirow[t]{2}{*}{ Response } & private & 156 & 3.95 & 0.835 & 0.067 & \multirow{2}{*}{7.469} & \multirow{2}{*}{0.000} \\
\hline & Public & 294 & 3.28 & 0.944 & 0.055 & & \\
\hline \multirow[t]{2}{*}{ Assurance } & private & 156 & 4.18 & 0.667 & 0.053 & \multirow{2}{*}{9.685} & \multirow{2}{*}{0.000} \\
\hline & Public & 294 & 3.31 & 1.013 & 0.059 & & \\
\hline \multirow[t]{2}{*}{ Empathy } & private & 156 & 3.95 & 0.763 & 0.061 & \multirow{2}{*}{5.189} & \multirow{2}{*}{0.000} \\
\hline & Public & 294 & 3.46 & 1.056 & 0.062 & & \\
\hline
\end{tabular}


Independent variables

Dependent

variable

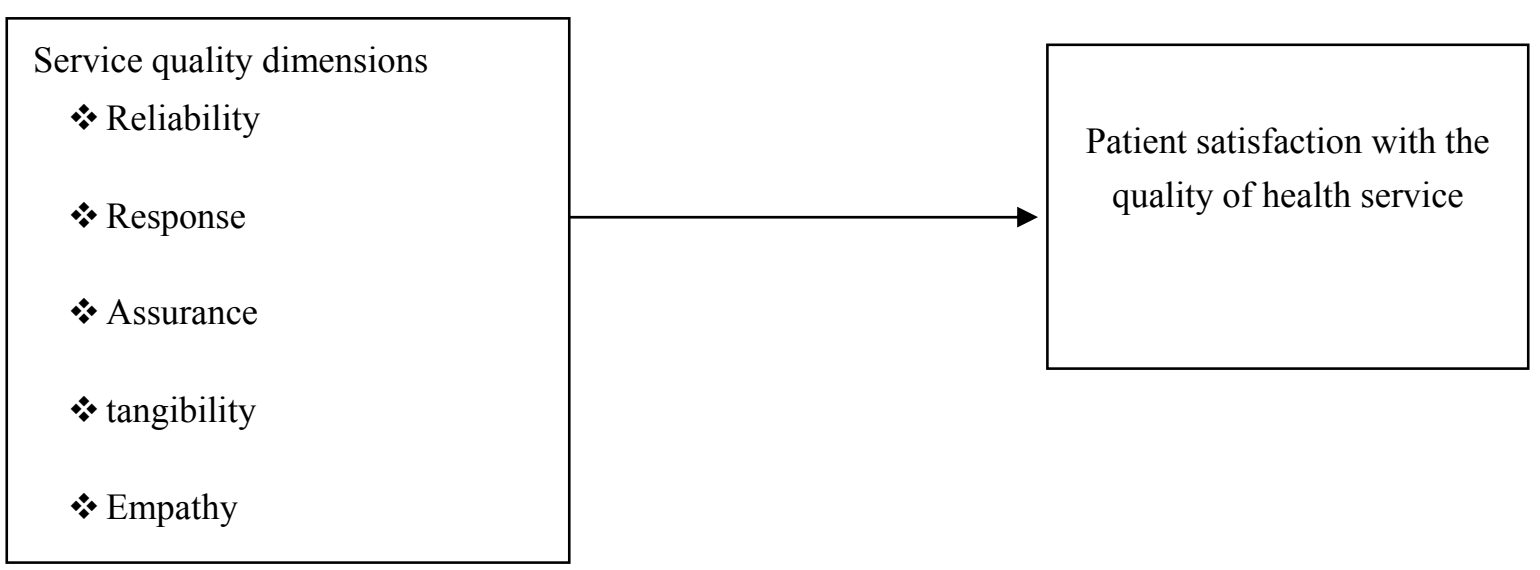

Figure 1. Dependent \& independent variables variable 